\title{
Long-term follow-up on the use of vascularized fibular graft for the treatment of congenital pseudarthrosis of the tibia Akio Sakamoto*1, Tatsuya Yoshida ${ }^{1}$, Yoshio Uchida1,2, Tetsuo Kojima1,3, Hideaki Kubota ${ }^{4}$ and Yukihide Iwamoto ${ }^{1}$
}

\author{
Address: ${ }^{1}$ Department of Orthopaedic Surgery, Graduate School of Medical Sciences, Kyushu University, Fukuoka, Japan, ${ }^{2}$ Uchida Orthopaedic \\ Surgery Hospital, Fukuoka, Japan, ${ }^{3}$ Mizoguchi Orthopaedic Surgery Hospital, Fukuoka, Japan and ${ }^{4}$ Saga Handicapped Children's Hospital, Saga, \\ Japan \\ Email: Akio Sakamoto* - akio@med.kyushu-u.ac.jp; Tatsuya Yoshida - yoshidat@ortho.med.kyushu-u.ac.jp; \\ Yoshio Uchida - uchida101@jcom.home.ne.jp; Tetsuo Kojima - kojimat@mpd.biglobe.ne.jp; Hideaki Kubota - ssgkubot@po.saganet.ne.jp; \\ Yukihide Iwamoto - yiwamoto@ortho.med.kyushu-u.ac.jp \\ * Corresponding author
}

Published: 6 March 2008

Journal of Orthopaedic Surgery and Research 2008, 3:13 doi:10.1 186/1749-799X-3-13

This article is available from: http://www.josr-online.com/content/3/1/13

(C) 2008 Sakamoto et al; licensee BioMed Central Ltd.

This is an Open Access article distributed under the terms of the Creative Commons Attribution License (http://creativecommons.org/licenses/by/2.0), which permits unrestricted use, distribution, and reproduction in any medium, provided the original work is properly cited.
Received: 30 May 2007

Accepted: 6 March 2008

\begin{abstract}
Background: Congenital pseudoarthrosis of the tibia (CPT) is one of the most difficult conditions to treat.

Methods: Five girls and 3 boys with CPT were treated by vascularized fibular grafting (VFG). The average age at VFG was 7.0 years (range: I.9-I I.5 years) with an average follow-up term of II.7 years (range: 4.9-19.6 years). Five of the children had undergone multiple operations before VFG, while the other 3 had no such history.

Results: Bone consolidation was obtained in all cases after an average term of 6.6 months (range: 4-10 months); this was with the first VFG in 7 cases but with the second VFG in I case. Complication of stress fracture and ankle pain occurred in I and 3 cases, respectively, only in cases undergoing multiple operations. Leg-length discrepancy was more prominent in the patients with multiple previous operations (mean: $7.5 \mathrm{~cm}$ ), than in the cases with no prior surgery (mean: $0.7 \mathrm{~cm}$ ).
\end{abstract}

Conclusion: The long-term results of VFG for CPT were excellent, especially in the cases, with no prior surgery. VFG should be considered as a primary treatment option for CPT.

\section{Background}

Congenital pseudoarthrosis of the tibia (CPT) is one of the most difficult conditions to treat. The natural history is persistent instability and progressive deformity $[1,2]$. CPT is known to accompany NF1 (neurofibromatosis type 1), also called von Recklinghausen disease. Treatment options vary, including both surgical and non-surgical approaches. Surgical techniques of vascularized fibular grafting (VFG), intramedullary stabilization and external fixation have been reported to be relatively successful in the treatment of CPT [3-9].

We previously reported the cases of 5 patients with CPT for whom good short-term results were obtained with the use of VFG [3]. However, long-term follow-up studies of VFG, particularly identifying limb-length discrepancy, residual angular deformity and the rates of refracture are necessary. All of those complications can compromise the 
functional outcome, even though pseudarthrosis may demonstrate bone consolidation $[2,10]$. In this study, the long-term results of VFG were evaluated for 5 previously reported cases and for an additional 3 cases. We specifically emphasize a comparison between patients undergoing multiple operations and those with no prior surgery before VFG. The previous surgerical procedures were in the current series were all intramedullary stabilization with/without bone grafting, which was not accompanied by any method of microvascular bone transplantation.

\section{Methods}

This is a retrospective review of the clinical results in 8 patients with CPT managed with VFG performed by Y.U. or T.K. at Kyushu University Hospital (Table 1). The patients comprised 5 girls and 3 boys. Six of them had NF1 $(6 / 8 ; 75 \%)$. The tibia with pseudarthrosis involved the right side in 5 cases and the left side in 3 cases. Ipsilateral VFG was applied as a first choice, and contralateral VFG was undertaken when ipsilateral fibula was not available. Consequently, ipsilateral VFG was applied in 7 cases and contralateral VFG was applied in 2 cases, in which one was for the initial trial of VFG, and the other was for the second trial of VFG after failure of bone consolidation in ipsilateral VFG.

Multiple previous operations had been performed before VFG in 5 patients in other institutions prior to attending our hospital. We have reported these patients in a study of short-term follow-up [3]. For these patients, the number of operations ranged from 3 to 8 , the average number being 3.4. The previous surgical treatments were all utilizing intramedullary nails with/without bone grafting. The other 3 patients were added for the purpose of the current study, and they had undergone no previous treatments. We analyzed the term of bone consolidation, and complications comprising leg-length discrepancy, tibial deformity of angulation, occurrence of fractures and existence of ankle pain, in a comparison between patients with and without previous surgical treatment before VFG. Bone consolidation was analyzed by skilled orthopedic surgeons including some of the authors.

\section{Operative technique}

The method of VFG is summarized as follows: Before operation, the vascular anatomy was determined by angiography. Dissection of the vascularised (peroneal vessels) fibula was performed. The fibula proximal to the pseudoarthrosis site was usually used for the donor. The thick fibrous tissue around the tibial pseudarthrosis was resected completely, whereas resection of the sclerotic bone ends was minimal. After correction of angular deformity, a slot was created to receive the fibular graft which was secured by several screws. End-to-end anasto- mosis was performed between the anterior tibial and the peroneal vessels [3].

\section{Statistical analysis}

Clinical data were statistically analyzed using the MannWhitney $U$-test for quantitative data of the term of bone consolidation and leg-length discrepancy, and using Fisher's exact test for qualitative data of the existence of ankle pain. A p value of less than 0.05 was considered to indicate statistical significance.

\section{Results}

Patients

The mean age of the patients at the time of VFG surgery was 7.0 years old (ranging from 1.9 to 11.5 years old). Average postoperative follow-up term was 11.7 years (ranging from 4.9 to 19.6 years), and the average patient age at final follow-up was 19.3 years old (ranging from 8.1 years to 27.3 years old). Recurrence was not seen in any of the cases during the course of the follow-up.

\section{Bone consolidation}

Bone consolidation after VFG occurred in all the patients (8/8: 100\%). In the patients undergoing multiple operations, all 5 cases obtained bone consolidation after the first VFG operation without any further surgery (Figs. 1, 2 ), while 1 out of the 3 cases without prior surgery failed to obtain bone consolidation following the first ipsilateral VFG at the age of 1.9 years old. A second contralateral VFG was then undertaken for this patient at the age of 7.3 years old, and bone consolidation was obtained 5 months after the second operation (Case 6; Fig. 3). Counting the second VFG in this case as data, the bone consolidation term of all 8 cases averaged 6.6 months (ranging from 4 to 10 months), in which bone consolidation was obtained 7 months after the second operation in this case. In the cases with no prior surgery, two out of the 3 patients obtained bone consolidation within 10 months. The bone consolidation term for the patients undergoing multiple operations was 6.8 months, while that for patients with no prior surgery was 6.3 months. There was no significant difference between these results $(\mathrm{p}=0.77)$.

\section{Complications}

\section{Leg-length discrepancy}

The overall average postoperative discrepancy in all cases was $4.9 \mathrm{~cm}$ (ranging from 0 to $15.7 \mathrm{~cm}$ ). The leg-length discrepancy for the cases undergoing multiple operations was $7.5 \mathrm{~cm}$ (ranging from 0.6 to $15.7 \mathrm{~cm}$ ), while that of cases with no prior surgery was $0.7 \mathrm{~cm}$ (ranging from 0.0 to $2.0 \mathrm{~cm})(\mathrm{p}=0.07)$. A discrepancy of more than $5.0 \mathrm{~cm}$ was seen in 4 out of the 5 cases undergoing multiple operations, but in none of the 3 cases with no prior surgery. For cases undergoing multiple operations, leg-length discrepancy with an average of $6.8 \mathrm{~cm}$ (ranging from 0.0 to 
Table I: Vascularized bone-transferred cases with/without previous multiple operations

\begin{tabular}{|c|c|c|c|c|c|c|c|c|c|c|}
\hline $\begin{array}{l}\text { Case/Side/ } \\
\text { NFI }\end{array}$ & Sex/Age & $\begin{array}{l}\text { Number of } \\
\text { previous } \\
\text { operations }\end{array}$ & Donor site & $\begin{array}{l}\text { Term until } \\
\text { union }\end{array}$ & $\begin{array}{c}\text { Age at follow-up } \\
\text { (term) }\end{array}$ & $\begin{array}{l}\text { Leg-length } \\
\text { discrepancy } \\
\text { (before VFG) }\end{array}$ & $\begin{array}{c}\text { Residual } \\
\text { angulations } \\
\text { anterior/valgus }\end{array}$ & $\begin{array}{l}\text { Stress fracture } \\
\text { (after VFG) }\end{array}$ & $\begin{array}{l}\text { Corrective } \\
\text { osteotomy }\end{array}$ & $\begin{array}{c}\text { Ankle pain } \\
\text { (after VFG) }\end{array}$ \\
\hline \multicolumn{11}{|c|}{ Cases with previous multiple operations } \\
\hline $\mathrm{I} / \mathrm{L} /+$ & F/7.4 уо & 8 & I & $9 \mathrm{~m}$ & 27.0 уо (19.6 y) & $5.2 \mathrm{~cm}(5.0)$ & $28 / 10 \mathrm{deg}$ & $+(4 \mathrm{~m})$ & - & $+(12 y)$ \\
\hline 2/L/+ & F/8.8 yo & 3 & I & $6 \mathrm{~m}$ & 21.6 уо (12.8 y) & $5.8 \mathrm{~cm}(6.0)$ & $21 / 0 \mathrm{deg}$ & - & - & $+(9 y)$ \\
\hline 3/L/+ & F/8.8 yo & 7 & I & $5 \mathrm{~m}$ & 27.3 уо (19.0 y) & $10.2 \mathrm{~cm}(9.0)$ & $5 / 3 \mathrm{deg}$ & - & - & - \\
\hline 4/R/- & $M / 8.9$ уо & 4 & C & $5 \mathrm{~m}$ & 22.2 уо (13.3 y) & $0.6 \mathrm{~cm}(0.0)$ & $18 / 2 * *$ deg & - & + & $+(I I y)$ \\
\hline $5 / R /+$ & F/II.5 yo & 6 & 1 & $9 \mathrm{~m}$ & 18.5 yo $(7.0$ y) & $15.7 \mathrm{~cm}(14.2)$ & $0 / 0$ deg & - & - & - \\
\hline \multicolumn{11}{|c|}{ Cases without prior surgery } \\
\hline \multirow[t]{2}{*}{ 6/R/- } & $M / 1.9$ yo & 0 & I & Non union & & & & & & \\
\hline & 17.3 yo & $I^{*}$ & C & $5 \mathrm{~m}$ & 14.8 уо (7.4 y) & $0.0 \mathrm{~cm}$ & $0 / 0 * *(22 / 20) \mathrm{deg}$ & - & + & - \\
\hline $7 / R /+$ & $M / 3.2$ yо & 0 & 1 & $10 \mathrm{~m}$ & 8.1 yo $(4.9 y)$ & $0.0 \mathrm{~cm}$ & $20 / 20 \mathrm{deg}$ & - & - & - \\
\hline $8 / R /+$ & $\mathrm{F} / 6.2$ yo & 0 & I & $4 \mathrm{~m}$ & 15.3 yо $(9.1$ y) & $2.0 \mathrm{~cm}$ & $0 / 0 \mathrm{deg}$ & - & - & - \\
\hline
\end{tabular}

*; First trial of vascularized bone-transferred operations, **; data after corrective osteotomy, NFI; neurofibromatosis type I, VFG; vascularized fibular grafting, L; left, R; right, M; male, F; female, yo; years old, y; years, m; months, l; ipsilateral, C; contralateral, ant; anterior, valg; valgus, deg; degrees. 

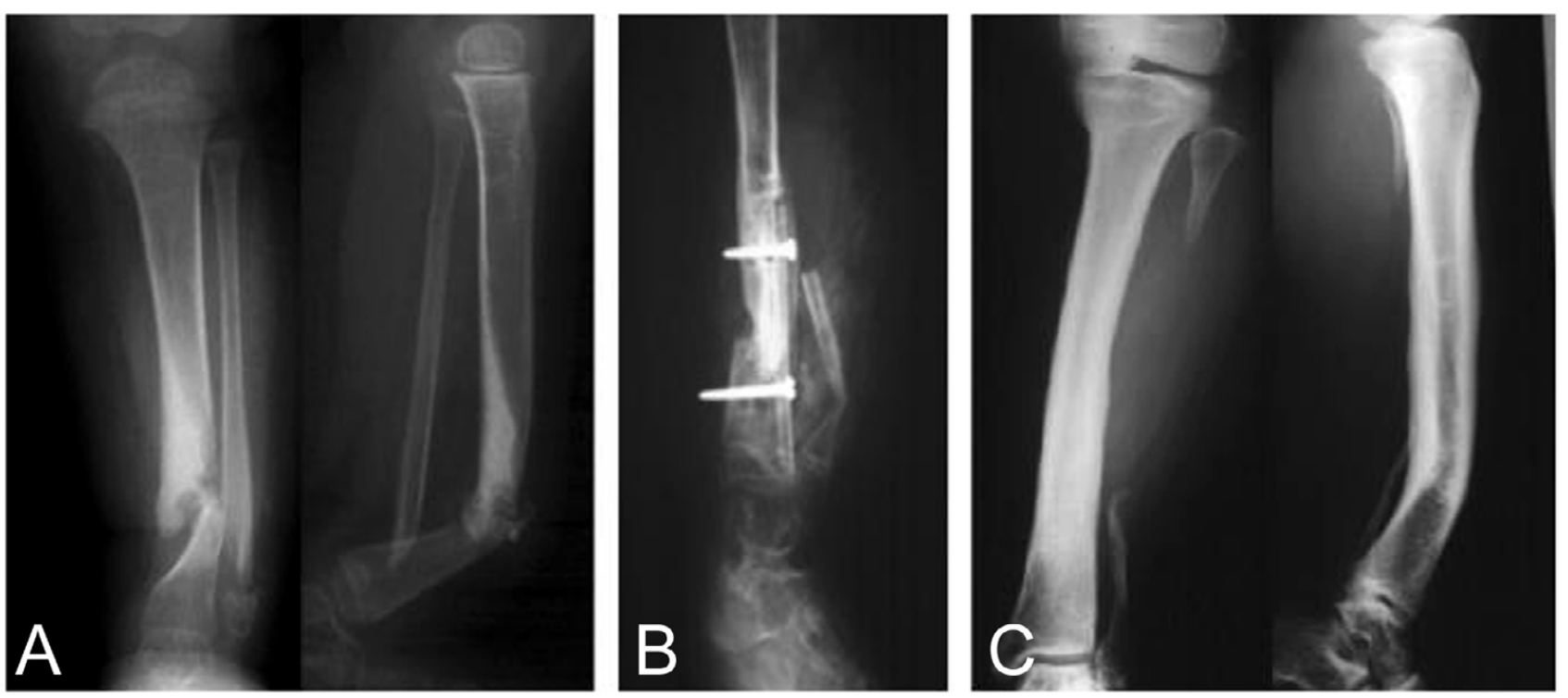

\section{Figure I}

Congenital pseudarthrosis of the tibia (Case I; a case undergoing multiple operations). Eight operations was undergone before VFG at 2.5 years old (A), Ipsilateral VFG was performed at 7.4 years old (B). At 23.5 years old, I5 years after VFG (C).

$14.2 \mathrm{~cm}$ ) already existed. Therefore there was no significant difference between the previous state $(6.8 \mathrm{~cm})$ and the post state $(7.5 \mathrm{~cm})$ of VFG in the group of cases undergoing multiple operations $(\mathrm{p}=0.84)$. The discrepancy seemed to be related to the earlier surgical procedures prior to VFG.

Tibial deformity of angulationDeformity of angulation varied, with the tibial valgus ranging from almost zero to 28.0 degrees and anterior bowing ranging from almost zero to 20.0 degrees. Deformity of more than 20 degrees occurred in 4 out of the 8 patients $(4 / 8 ; 50 \%)$, of which 2 were cases undergoing multiple operations $(2 / 5 ; 40 \%)$ and 2 were cases with no prior surgery $(2 / 3 ; 67 \%)$. Two cases had undergone corrective osteotomy, of which one had undergone multiple operations and the other had undergone no prior surgery (Cases 4, 6).

\section{Fractures}

One patient had a stress fracture 4 months after VFG (Case $1)$. The fracture was treated with a brace and it healed.

\section{Ankle pain}

Ankle pain was seen in 3 out of the 8 cases, regardless of its severity. These pains appeared 12 years (at 19 years old), 9 years (at 17 years old) and 11 years (at 19 years old) after the surgery. The average term was 10.6 years and the average age was 18.3 years old. It seemed to be characteristic that these pains appeared at late adolescence. These cases of ankle pain seemed to be associated with the degree of tibial angulation. Moreover, ankle pain was seen in 3 out of the 5 cases undergoing multiple operations, but in none of the 3 cases with no prior surgery $(\mathrm{p}=0.08)$.

\section{Other factors}

Gender or the existence of NF1 did not seem to have any relationship with bone consolidation or any other complications.

\section{Discussion}

In a series of VFG for the treatment of CPT, bone consolidation was reported to be obtained in $94 \%$ of cases [4]. In the current study, all cases with VFG obtained bone consolidation, with an average bone consolidation term of 6.6 months without recurrence. In a previous report, gender may have been a significant factor in the length of term needed for bone consolidation, on the basis that 13 boys had an average bone consolidation term of 13 months, whereas 16 girls had an average bone consolidation term of 9 months [2]. In the current case, such a tendency was not observed. In our institute, because of good results of bone consolidation after VFG, VFG has been chosen as the primary treatment, with the Ilizarov bone transport method being an alternative choice. In a previous report, the Ilizarov bone transport method was reported as being useful in achieving primary healing in CPT, but complications of refracture and postoperative deformities may occur [11]. Further examination of longterm follow-up after the Ilizarov bone transport method is necessary. 

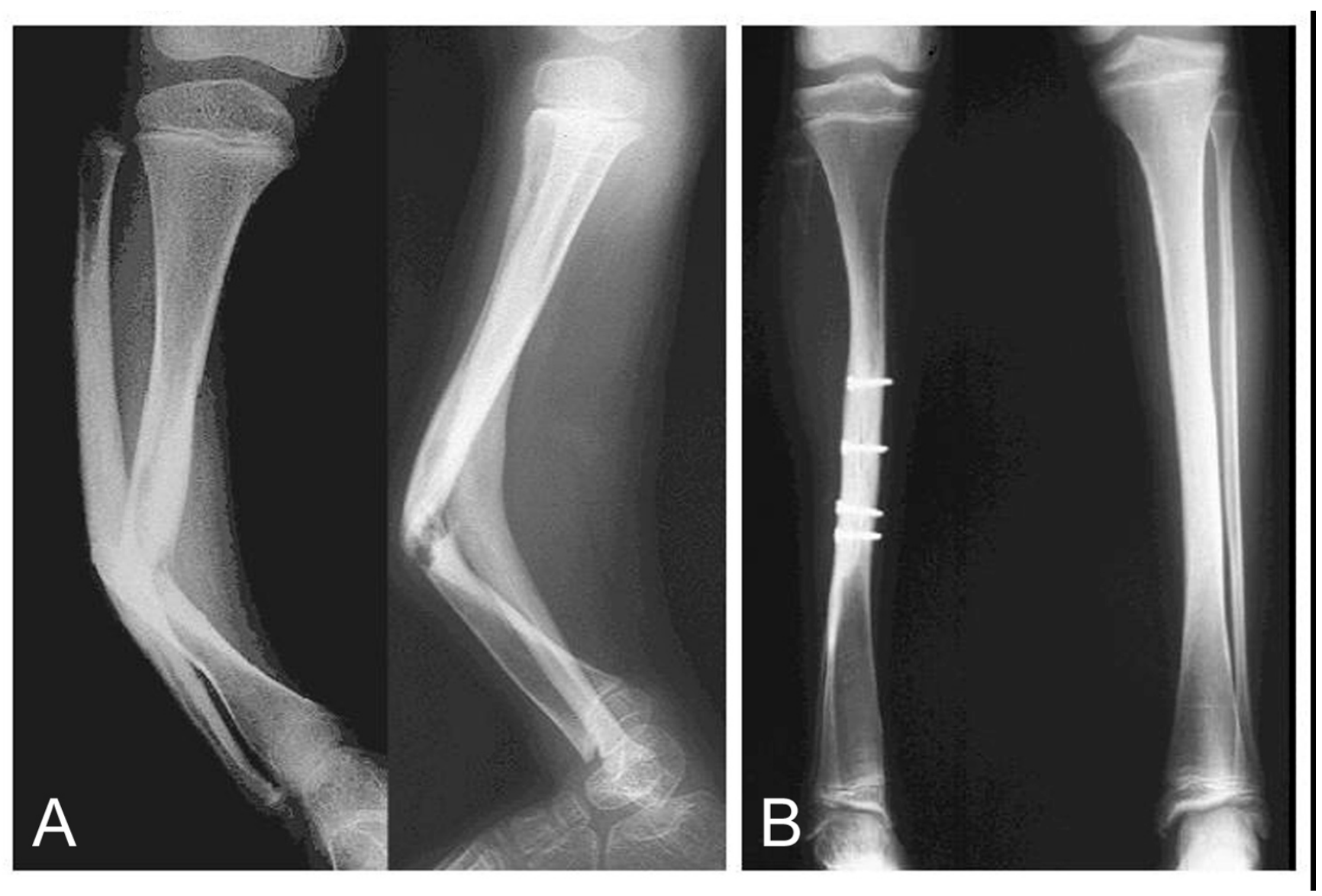

Figure 2

Congenital pseudarthrosis of the tibia (Case 8; a case with no prior surgery) with no other operation before VFG. Preoperation status at 6.6 years old (A). At 12.8 years old, 6.2 years after VFG (B).

As for VFG, it has been reported that age is an important factor in the result of VFG, with regard to bone consolidation. In a previous report, seven patients operated on at 10 years of age or older had successful outcomes, compared with 12 out of 22 who were 9 years of age or younger at the time of surgery [12]. According to the EPOS (European Paediatric Orthopaedic Society) Multicenter Study [6], there was a clear correlation between age at surgery and final outcome, with better results being achieved with increasing age. Therefore, it has been proposed that surgery should not be performed on patients younger than the age of 3 years and it is recommended that surgery be postponed until the age of 5 years [6]. Another study about bone consolidation in CPT also suggested that the best age for rapid bone consolidation is 3.5 years to 7.5 years old [4]. In the current study, one case aged 1.9 years old did not obtain bone consolidation with VFG. For that case, a second contralateral VFG was successful at the age of 7.3 years old. This fact may support the notion that an age younger than 3 or 3.5 years old is a negative factor with regard to bone consolidation in VFG.
Tibial deformities of limb-length discrepancy and angulation are common after treatment for CPT $[2,4]$. Bone consolidation of pseudarthrosis is not sufficient for assessment as the end result. Occasionally, chronic lowerextremity dysfunction and clinical symptoms may result in amputation [7]. In the current series, a limb-length discrepancy of more than $5 \mathrm{~cm}$ was seen in 4 out of the 5 cases undergoing multiple operations but in none of the 3 cases with no prior surgery. The average leg-length discrepancy for the cases undergoing multiple operations was $7.5 \mathrm{~cm}$, while that of cases with no prior surgery was $0.7 \mathrm{~cm}$. The p value is 0.07 , and the reason for there being no significant difference statistically may be because of the small number of these cases. Limb-length discrepancy has been reported in half the patients with intramedullary nails [7]. Such surgical procedures with a potential danger of damaging the growth plate may result in limb-length discrepancy. Therefore, the deformity may have been related to an earlier surgical procedure prior to VFG [12]. 

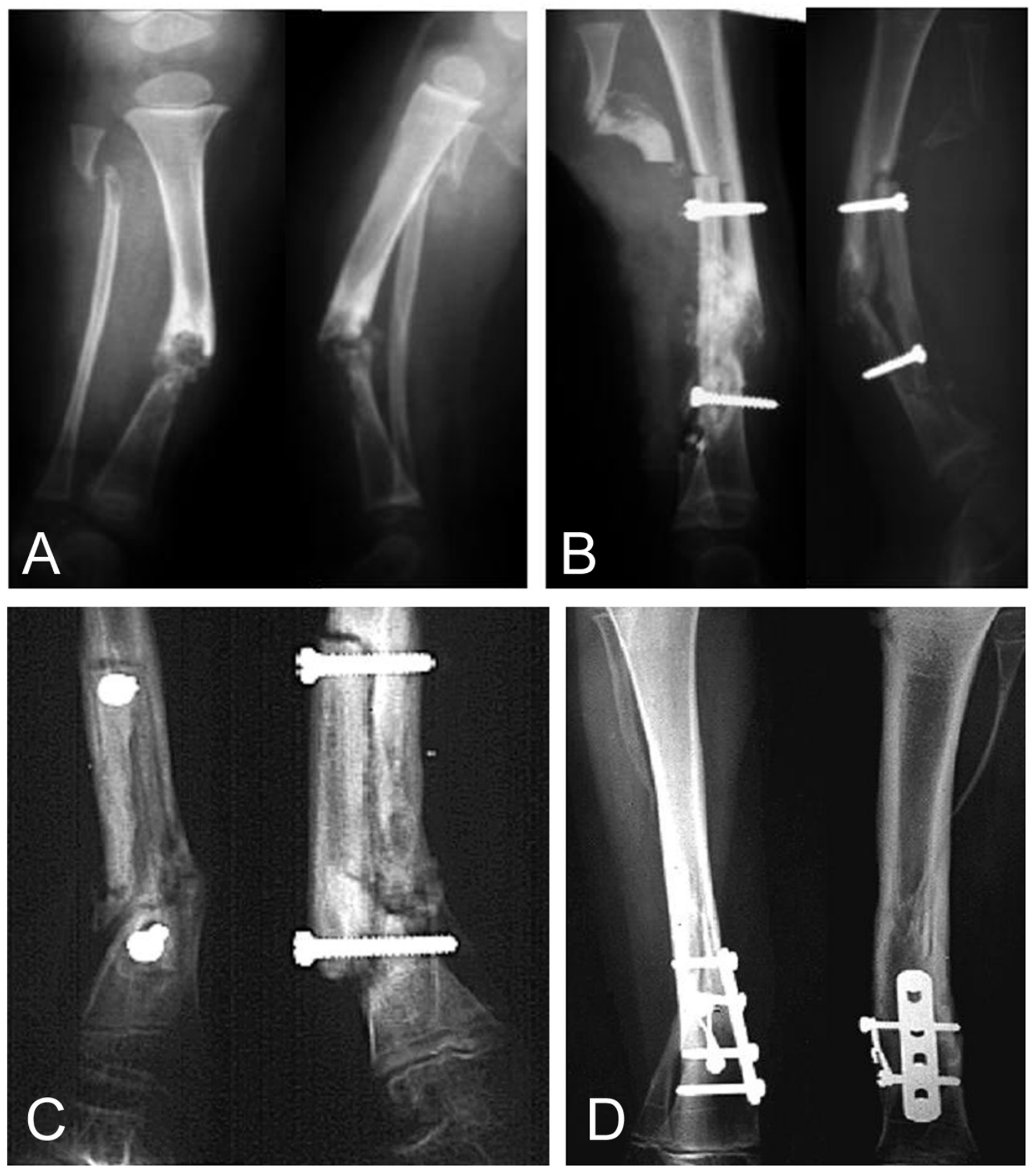

Figure 3

Congenital pseudarthrosis of the tibia (Case 6; a case with no prior surgery). Preoperation status of VFG (A). Ipsilateral VFG was performed at 1.9 years old (B). At 7.3 years old, bone consolidation can be seen 5 months after second VFG from the contralateral side (C). At I4.8 years old, after corrective osteotomy of the lower tibia for the deformity (D). 
Angular deformities do not remodel and are often progressive after VFG $[5,13]$. In the current study, a deformity of more than 20 degrees was seen in 4 out of the 8 cases. The relationship between the degree of angulation and multiple operations before VFG is not clear. Ankle pain was seen in 3 out of 8 cases. It seemed characteristic that these pains appeared long after the VFG (mean, 10.6 years), and late in the second decade (mean, 18.3 years old). These 3 cases had undergone multiple operations. Therefore, it should perhaps be noted that there was a tendency for previous unoperated cases to have ankle pain at long-term follow-up, even though there had been no pain of short-term follow-up. In a previous report, ankle pain after the surgical procedure for VFG is associated with multiple operations utilizing intramedullary nails, consistent with our results [14], and degenerative changes in the ankle because of the ankle valgus deformity and the intramedullary rod passing through the ankle joint is considered to be the cause of the ankle pain [14-16]. Refracture is not uncommon following consolidation of VFG $[13,17,18]$. In most cases, the first fracture is reported to occur before the age of 1 year [4]. In the current case, one out of the 8 cases had a stress fracture at the age of 7.4 years old, and casting healed the fracture.

\section{Conclusion}

In conclusion, the overall long-term follow-up results of VFG were excellent. However, residual limb-length discrepancy and ankle pain were prominent in cases undergoing multiple operations. In contrast, patients who underwent VFG as a primary operation had fewer such problems. Accordingly, VFG should be considered as a primary treatment option for CPT.

\section{Abbreviations}

CPT; congenital pseudarthrosis of the tibia, NF1; neurofibromatosis type 1, VFG; vascularized fibular graft, LLD; leg-length discrepancy

\section{Competing interests}

The author(s) declare that they have no competing interests.

\section{Authors' contributions}

AS drafted the manuscript. YU and TK performed vascularized fibular graft. AS, TY and HK participated in the design of the study. YI conceived of the study, and participated in its design and coordination and helped to draft the manuscript. All authors read and approved the final manuscript.

\section{Acknowledgements}

The patient's families were informed that data from the case would be submitted for publication, and gave their consent. The English used in this manuscript was revised by Miss K. Miller (Royal English Language Centre, Fukuoka, Japan)

\section{References}

I. Boyd HB: Pathology and natural history of congenital pseudarthrosis of the tibia. Clin Orthop Relat Res 1982:5-13.

2. Morrissy RT, Riseborough EJ, Hall JE: Congenital pseudarthrosis of the tibia. J Bone Joint Surg $\mathrm{Br}$ 198I, 63-B(3):367-375.

3. Uchida $Y$, Kojima T, Sugioka $Y$ : Vascularised fibular graft for congenital pseudarthrosis of the tibia. Long-term results. J Bone Joint Surg Br 199I, 73(5):846-850.

4. Gilbert A, Brockman R: Congenital pseudarthrosis of the tibia. Long-term followup of 29 cases treated by microvascular bone transfer. Clin Orthop Relat Res 1995:37-44.

5. Kanaya F, Tsai TM, Harkess J: Vascularized bone grafts for congenital pseudarthrosis of the tibia. Microsurgery 1996, 17(8)::459-69; discussion 470-I.

6. Grill F, Bollini G, Dungl P, Fixsen J, Hefti F, Ippolito E, Romanus B, Tudisco C, Wientroub S: Treatment approaches for congenital pseudarthrosis of tibia: results of the EPOS multicenter study. European Paediatric Orthopaedic Society (EPOS). J Pediatr Orthop B 2000, 9(2):75-89.

7. Dobbs MB, Rich MM, Gordon JE, Szymanski DA, Schoenecker PL: Use of an intramedullary rod for treatment of congenital pseudarthrosis of the tibia. A long-term follow-up study. J Bone Joint Surg Am 2004, 86-A(6): I I 86-I I 97.

8. Paley D, Catagni M, Argnani F, Prevot J, Bell D, Armstrong P: Treatment of congenital pseudoarthrosis of the tibia using the Ilizarov technique. Clin Orthop Relat Res 1992:81-93.

9. Guidera KJ, Raney EM, Ganey T, Albani W, Pugh L, Ogden JA: Ilizarov treatment of congenital pseudarthroses of the tibia. J Pediatr Orthop 1997, 17(5):668-674.

10. Leung PC: Congenital pseudarthrosis of the tibia. Three cases treated by free vascularized iliac crest graft. Clin Orthop Relat Res 1983:45-50.

II. Kristiansen LP, Steen H, Terjesen T: Residual challenges after healing of congenital pseudarthrosis in the tibia. Clin Orthop Relat Res 2003:228-237.

12. Romanus B, Bollini G, Dungl P, Fixsen J, Grill F, Hefti F, Ippolito E, Tudisco $C$, Wientroub S: Free vascular fibular transfer in congenital pseudoarthrosis of the tibia: results of the EPOS multicenter study. European Paediatric Orthopaedic Society (EPOS). J Pediatr Orthop B 2000, 9(2):90-93.

13. Weiland AJ, Weiss AP, Moore JR, Tolo VT: Vascularized fibular grafts in the treatment of congenital pseudarthrosis of the tibia. J Bone Joint Surg Am 1990, 72(5):654-662.

14. Inan M, El Rassi G, Riddle EC, Kumar SJ: Residual deformities following successful initial bone union in congenital pseudoarthrosis of the tibia. J Pediatr Orthop 2006, 26(3):393-399.

15. Andersen KS: Congenital pseudarthrosis of the tibia and neurofibromatosis. Acta Orthop Scand 1976, 47(I): 108-III.

16. Anderson DJ, Schoenecker PL, Sheridan J], Rich MM: Use of an intramedullary rod for the treatment of congenital pseudarthrosis of the tibia. J Bone Joint Surg Am 1992, 74(2): 16I-I68.

17. Dormans JP, Krajbich Jl, Zuker R, Demuynk M: Congenital pseudarthrosis of the tibia: treatment with free vascularized fibular grafts. J Pediatr Orthop 1990, I 0(5):623-628.

18. Minami $A$, Kaneda $K$, Itoga $H$, Usui M: Free vascularized fibular grafts. J Reconstr Microsurg 1989, 5(1):37-43.

Publish with Biomed Central and every scientist can read your work free of charge

"BioMed Central will be the most significant development for disseminating the results of biomedical research in our lifetime. "

Sir Paul Nurse, Cancer Research UK

Your research papers will be:

- available free of charge to the entire biomedical community

- peer reviewed and published immediately upon acceptance

- cited in PubMed and archived on PubMed Central

- yours - you keep the copyright

Submit your manuscript here:

http://www.biomedcentral.com/info/publishing_adv.asp
BioMedcentral 